\title{
Numerical Modeling of Tailings Thickening for Improved Mine Waste Management
}

\author{
S. Azam ${ }^{1, *}$, S. Jeeravipoolvarn ${ }^{2}$, and J. D. Scott ${ }^{2}$ \\ ${ }^{I}$ Environmental Systems Engineering, University of Regina, Regina, SK S4S 0A2, Canada \\ ${ }^{2}$ Department of Civil \& Environmental Engineering, University of Alberta, Edmonton, AB T6G 2W2, Canada
}

Received 7 October 2008; revised 10 January 2009; accepted 1 February 2009; published online 10 June 2009

\begin{abstract}
The environmental footprint of mining can be minimized by developing and improving the waste management technologies. Thickening involves the conversion of dilute tailings to paste-like materials with superior engineering and environmental properties. The process of tailings thickening is not well-understood in geotechnical engineering. The primary objective of this paper was to model the dewatering behavior of slurries during thickening. Two separate numerical models were developed using constitutive relationships based on the nonlinear finite strain consolidation theory and on the inclusion of a hindered sedimentation regime in the consolidation theory. In the coupled sedimentation-consolidation model, the transition zone was numerically modeled between a maximum suspension void ratio corresponding to the initial development of a distinct slurry microstructure and a structural void ratio referring to the development of a soil skeleton transferring effective stresses. For the investigated tailings material, sedimentation was found to be complete at $e_{\mathrm{m}}=8.0$ and consolidation was observed to start at $e_{\mathrm{s}}=6.5$. Both of the models closely matched at $e \leq 6.5$ confirming the validity of the coupled sedimentation-consolidation model.
\end{abstract}

Keywords: mine waste management, tailings thickening, numerical modeling, finite strain consolidation, hindered sedimentation, effective stress, void ratio, hydraulic conductivity

\section{Introduction}

Wet mineral processing generates large volumes of fluid tailings accumulated over the operational life of a mine. Generally, these wastes are contained in a disposal area with perimeter dykes constructed from the coarser fraction of the tailings material. The slow settling rates of the fines and the high standing toxic waters offer unique challenges pertaining to the management of the containment facilities for a number of decades beyond mine closure (Edil and Fox, 2000). Numerous tailings dam failures in different parts of the globe have been reported to result in massive contaminant releases causing acute public distress over the conventional practice of tailings disposal (Morgenstern and Scott, 1995). To minimize the environmental footprint of mining, a suite of waste management technologies have been developed over the years: one of the most promising being tailings thickening (Concha and Burger, 2003).

Thickening is the method by which slurries are converted to paste-like materials with superior geotechnical and environmental properties (Robinsky, 1999). The tailings stream modified through physicochemical reagents fulfills one or more of the following objectives: (i) reclaim process water and/or che-

\footnotetext{
${ }^{*}$ Corresponding author. Tel.: +1306 3372369; fax: +1 3065854855 .

E-mail address: Shahid.Azam@uregina.ca (S. Azam).
}

ISSN: 1726-2135 print/1684-8799 online

(C) 2009 ISEIS All rights reserved. doi:10.3808/jei.200900146 mical reagents; (ii) maximize the solids content of the tailings in the storage facility; (iii) minimize the potential for contamination; (iv) balance water consumption at various stages in the ore beneficiation process; and (v) develop suitable materials for surface deposition, mine backfilling, or sub-aqueous discharge (Jewell and Fourie, 2006). The gravity thickener (a cylindrical vessel with an inverted conical base) is used to dewater an initially dilute slurry feed through self-weight settling. Three observable zones in the thickener include a clear liquid at the top, an intermediate sedimentation zone, and a bottom consolidation zone. Allowing an upward drainage, the overflow is collected around the periphery at the top whereas the underflow is removed from the thickener bottom at regular intervals of time.

Modeling the dewatering behavior of slurries during thickening is not well understood in geotechnical engineering. Conventionally, sedimentation was considered to be affected by physicochemical factors whereas consolidation was believed to be largely a load-deformation process (Eckert et al., 1996). Recent studies have confirmed that complex colloid-water-additive phenomena govern hindered sedimentation (Azam et al., 2005) and have also shown the influence of such phenomena on large-strain consolidation (Azam et al., 2007). Assuming that consolidation is the mechanism describing the thickening process, tailings dewatering can be modeled using the one-dimensional nonlinear finite strain consolidation theory. This theory was originally developed to describe the behavior of soft soils and is based on the continuity of mixtures, the Darcy-Gersevanov fluid migration relationship through a soil matrix, and 
the Terzaghi principle of effective stress for vertical equilibrium (Been and Sills, 1981). To account for the presence of a distinct sedimentation phase (when physicochemical interactions are at a maximum), researchers have been trying to include sedimentation in the same analysis (Toorman, 1999). The main challenge is to determine the transition zone between sedimentation and consolidation. A clear understanding of appropriate modeling approaches is critical for the design and implementation of a sustainable tailings management program.

The main objective of this paper was to model the dewatering behavior of slurries during thickening. For this purpose, two separate numerical models were developed based on the nonlinear finite strain consolidation theory and on the inclusion of a hindered sedimentation regime in the consolidation theory. For model calibration, appropriate parameters for compressibility and hydraulic conductivity were obtained from a large-strain consolidation test on selected tailings. The models were evaluated using hindered sedimentation test data and verified for a hypothetical thickener under quiescent conditions.

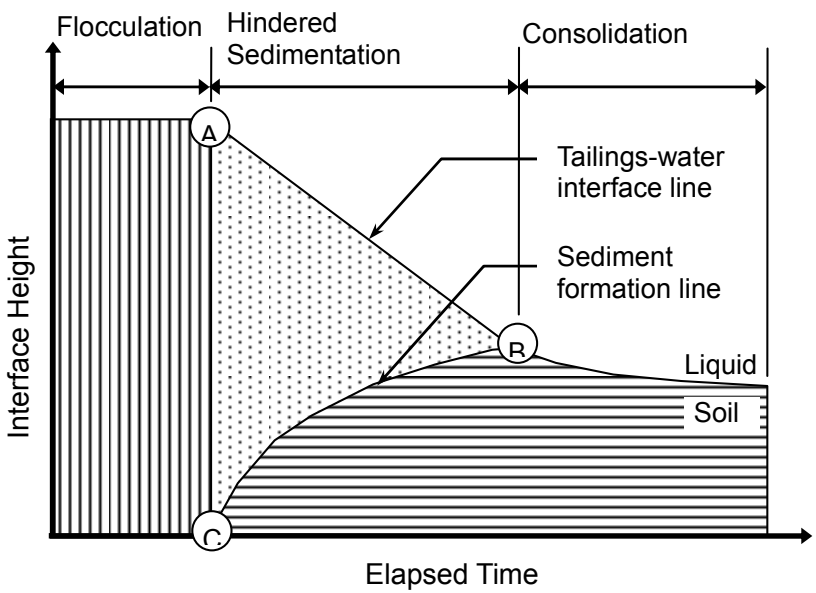

Figure 1. Settling of a slurry versus elapsed time (after Imai, 1981).

\section{Theoretical Background}

\subsection{Slurry Settling Phenomenology}

Figure 1 plots the settling of a slurry versus the elapsed time. The process consists of three distinct stages: flocculation, sedimentation, and consolidation (Imai, 1981). The slurry develops an initial fabric up to point ' $A$ ' or ' $C$ ' such that there is no appreciable change in the interface height. The microstructure is derived from the solid-liquid interactions and, in turn, depends on colloid mineralogy and water chemistry. The newly formed flocs allow the slurry to undergo a rapid decrease in the interface height from point ' $A$ ' through ' $B$ '. This hindered sedimentation regime refers to the settling of a spatial network of soil particles without measurable effective stress (McRoberts and Nixon, 1976). At the bottom, a sediment starts to form immediately after microstructure development in the slurry at point ' $\mathrm{C}$ '. The thickness of the sediment increases as depicted by the sediment formation line that eventually meets point ' $\mathrm{B}$ '.
This stage of slurry settling is known as consolidation and commences when the solid grains are in contact thereby transmitting effective stresses (Terzaghi et al., 1996). The sedimentation zone slowly transitions into the consolidation zone and finally there is clear water at the top and a soil at the bottom. The entire settling process can be modeled using the following modeling approaches.

\subsection{Nonlinear Finite Strain Consolidation Model}

Consolidation refers to change in soil volume resulting from the dissipation of excess pore pressure that, in turn, is provoked by the vertical stresses (Terzaghi et al., 1996). The rate of excess pore pressure dissipation is influenced by the excess pore pressure gradient and the hydraulic conductivity $(k)$ of the material. During this process, the soil matrix undergoes a continuous re-adjustment to satisfy the evolving equilibrium conditions. This is manifested by soil compressibility (de/d $\sigma)$, where $e$ is the void ratio and $\sigma^{\prime}$ is the effective stress; the effective stress, in turn, equals $\sigma-u_{w}$ where $\sigma$ is the total stress and $u_{w}$ is the pore water pressure. This classical consolidation theory assumes that the soil undergoes small deformations and that the soil parameters are constant.

To account for large settlements in soft soils such as tailings for which compressibility and hydraulic conductivity are nonlinear, Gibson et al. (1967) developed the nonlinear finite strain consolidation theory. The nonlinear behavior of soil was implemented through relationships determined from laboratory testing and the use of material coordinates allowed for capturing large deformations. Denoting the unit weight of soil solids by $\gamma_{s}$ and of water by $\gamma_{w}$, vertical material coordinate by $z$, and elapsed time by $t$, the governing equation for nonlinear finite strain consolidation can be written as follows:

$$
\left(\frac{\gamma_{s}}{\gamma_{w}}-1\right) \frac{d}{d e}\left(\frac{k}{1+e}\right) \frac{\partial e}{\partial z}+\frac{\partial}{\partial z}\left[\frac{k}{\gamma_{w}(1+e)} \frac{d \sigma^{\prime}}{d e} \frac{\partial e}{\partial z}\right]+\frac{\partial e}{\partial t}=0
$$

\subsection{Coupled Sedimentation-Consolidation Model}

The classical kinematical theory of sedimentation considers the solid phase as a continuum and represents slurry settling using the continuity equation assuming that the settling velocity $\left(V_{s}\right)$ is a function of the solids volumetric concentration only (Kynch, 1952). This rationale is quite similar to the nonlinear finite strain consolidation theory thereby allowing the combination of the two settling regimes. The main issue in such coupling lies in the fundamental assumption of the two theories: consolidation is based on the effective stress principle, that is, changes in soil volume are considered to result from changes in effective stress whereas effective stress is theoretically non-existent during hindered sedimentation. By modifying the effective stress principle and denoting total stress by $\sigma$, effective stress by $\sigma^{\prime}$, and pore pressure by $u_{w}$, Pane and Schiffman (1985) included the hindered sedimentation regime in the finite strain consolidation theory using an interaction coefficient $(\beta)$ as per the following equation:

$\sigma=\beta \sigma^{\prime}+u_{w}$ 
The dimensionless term $\beta$ is assumed to be a function of void ratio $(e)$ that gradually increases from 0.0 (for a suspension without generating effective stresses, that is, sedimentation) to 1.0 (for a soil matrix transmitting effective stresses, that is, consolidation) during thickening. Jeeravipoolvarn et al. (2009) extensively discussed the use of this coefficient in the coupled sedimentation-consolidation modeling. Using the interaction coefficient, the governing equation for one-dimensional coupled sedimentation-consolidation can be expressed as follows (Pane and Schiffman, 1985):

$$
\begin{aligned}
& \left(\frac{\gamma_{s}}{\gamma_{w}}-1\right) \frac{d}{d e}\left(\frac{k}{1+e}\right) \frac{\partial e}{\partial z}+\frac{\partial}{\partial z}\left[\frac{k}{\gamma_{w}(1+e)} \beta \frac{d \sigma^{\prime}}{d e} \frac{\partial e}{\partial z}\right] \\
& +\frac{\partial}{\partial z}\left[\frac{k}{\gamma_{w}(1+e)} \sigma^{\prime} \frac{d \beta}{d e} \frac{\partial e}{\partial z}\right]+\frac{\partial e}{\partial t}=0
\end{aligned}
$$

Table 1. Material Properties of the Investigated Tailings

\begin{tabular}{|c|c|c|}
\hline & Property & Value \\
\hline \multirow[t]{3}{*}{$\begin{array}{l}\text { Solid } \\
\text { Chemistry }\end{array}$} & Minerals (\%) & $\begin{array}{l}\text { Goethite }(50 \pm 5) \text {; Hematite } \\
(20 \pm 5) \text {; Maghemite }(20 \pm \\
5) ; \text { Chrysotile }(10 \pm 5)\end{array}$ \\
\hline & $\begin{array}{l}\text { Cation Exchange } \\
\text { Capacity, CEC } \\
(\mathrm{cmol}(+) / \mathrm{kg})\end{array}$ & 7.6 \\
\hline & $\begin{array}{l}\text { Anion Exchange } \\
\text { Capacity, AEC } \\
(\mathrm{cmol}(-) / \mathrm{kg})\end{array}$ & 6.8 \\
\hline \multirow{4}{*}{$\begin{array}{l}\text { Water } \\
\text { Chemistry }\end{array}$} & $\mathrm{pH}$ & 7.2 \\
\hline & $\begin{array}{l}\text { Electrical } \\
\text { Conductivity, } \\
\text { EC }(\mu \mathrm{S} / \mathrm{cm})\end{array}$ & 744.0 \\
\hline & $\begin{array}{l}\text { Dissolved Ions } \\
(\mathrm{mg} / \mathrm{L})\end{array}$ & $\begin{array}{l}\mathrm{Na}^{+}(17) ; \mathrm{K}^{+}(1.1) ; \mathrm{Ca}^{2+} \\
(19.5) ; \mathrm{Mg}^{2+}(87) ;\end{array}$ \\
\hline & & $\begin{array}{l}\mathrm{Cl}^{-}(28.4) ; \mathrm{NO}_{3}{ }^{-}(1.3) ; \\
\mathrm{HCO}_{3}{ }^{-}(24) ; \mathrm{SO}_{4}{ }^{2-}(386)\end{array}$ \\
\hline \multirow[t]{3}{*}{$\begin{array}{l}\text { Index } \\
\text { Properties }\end{array}$} & $\begin{array}{l}\text { Specific Gravity, } \\
\text { GS }\end{array}$ & 3.15 \\
\hline & $-0.075 \mathrm{~mm}(\%)$ & 93.0 \\
\hline & $-0.002 \mathrm{~mm}(\%)$ & 35.0 \\
\hline
\end{tabular}
(Azam et al., 2005)

\section{Laboratory Investigations}

\subsection{Material Composition}

Table 1 summarizes the material properties of the selected tailings slurry provided by the Metallurgical Technologies Division of Dynatec Corporation, Canada. The tailings solids primarily consisted of heavy iron oxides (goethite, hematite, and maghemite) and chrysotile clay minerals, all of which cumulatively resulted in a specific gravity $(G s)$ of 3.15 . The exchange capacities correlated well with the observed mineralogy of the solids. The high specific gravity of the solids together with the near neutral pore water and the low dissolved ions were expected to result in rapid settling of the tailings. In addition, the predominantly fine-grained solids containing $10 \pm 5 \%$ chryso- tile clay mineral were likely to cause physicochemical interactions thereby affecting the dewatering behavior of the investigated tailings.

\subsection{Large-Strain Consolidation Testing}

A large-strain consolidation test was conducted to calibrate the models, that is, to determine the modeling parameters from the constitutive relationships for compressibility $(e-$ $\left.\sigma^{\prime}\right)$ and hydraulic conductivity $(k-e)$. The tailings sample was initially allowed to settle under self-weight and subsequently subjected to external loading applied in increments. Each load was applied when no more change in void ratio was observed under the previous load. To simulate the thickening process, an upward drainage was allowed using the hydraulic gradient between a bottom injection tube and a top collection tube. This arrangement was further utilized to determine the hydraulic conductivity at the end of each load increment according to the ASTM Standard Test Method for Permeability of Granular Soils (Constant Head) [D2434-68(2006)]. The hydraulic conductivity $(k, \mathrm{~cm} / \mathrm{sec})$ was calculated from knowledge of flow volume $\left(Q, \mathrm{~cm}^{3} / \mathrm{sec}\right)$ collected in time $(t, \mathrm{sec})$, sample height $(L, \mathrm{~cm})$, surface area $\left(a, \mathrm{~cm}^{2}\right)$ and head difference $(h, \mathrm{~cm})$ according to the following version of Darcy's law:

$k=\frac{Q L}{a h}$

The void ratio was determined and plotted versus the elapsed time. The effective stress corresponding to each load increment was calculated from knowledge of excess pore pressure. The void ratio at the end of each load was plotted versus the resulting effective stress and the hydraulic conductivity measured at the end of each load was plotted versus the void ratio. The best-fit parameters from both of these relationships were used in numerical modeling.

\subsection{Hindered Sedimentation Testing}

A bench-scale hindered sedimentation test was conducted using a $133 \mathrm{~mm}$ diameter graduated standpipe. The laboratorymeasured test data (interface height versus elapsed time) were used for model validation whereas the processed data (included as initial points in the above mentioned constitutive relationships) were used for model calibration. The slurry at an initial solids content of $15 \%$ (that ensured negligible segregation) was allowed to settle under gravity. To facilitate visual observation of the fast moving interface through an opaque fluid, the initial sample height was kept as $133 \mathrm{~mm}$ and the resulting height to diameter ratio of 1.0 at the test start minimized wall effects (Azam et al., 2005). The solid-liquid interface movement was captured at regular time intervals using a camcorder with macro lenses for up to 7 times image magnification. The camcorder was connected to a computer that stored the captured frames in a digital format. After test completion, the enlarged digital frame files were carefully viewed and the observed data were recorded as tailings-water interface settlement versus time. The slope of the initial straight-line portion of the sedimenta- 
tion curve was used to determine initial hydraulic conductivity $\left(k_{i}, \mathrm{~cm} / \mathrm{sec}\right)$, using the Pane and Schiffman (1997) formulation. From the interface settling velocity $\left(V_{s}, \mathrm{~cm} / \mathrm{sec}\right)$, the initial void ratio $\left(e_{i}\right)$, and the unit weights of soil solids $\left(\gamma_{s}, \mathrm{kN} /\right.$ $\left.\mathrm{m}^{3}\right)$ and of the water $\left(\gamma_{w}, \mathrm{kN} / \mathrm{m}^{3}\right), k_{i}$ was determined according to the following simplified equation:

$k_{i}=\frac{\gamma_{w} V_{s}\left(1+e_{i}\right)}{\gamma_{s}-\gamma_{w}}$
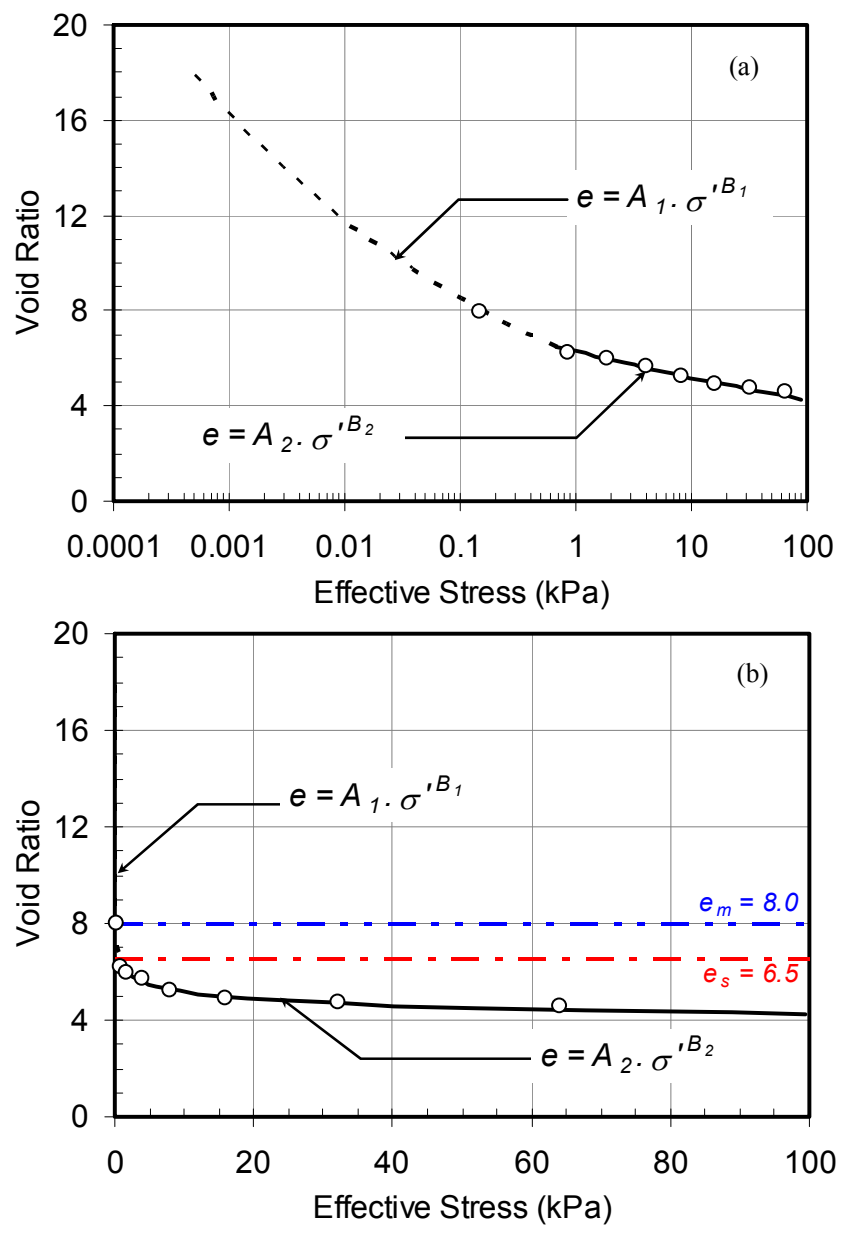

Figure 2. Tailings compressibility: (a) logarithmic scale and (b) arithmetic scale.

\section{Model Calibration}

Figure 2 gives the laboratory-determined compressibility of the selected tailings using the processed data from the largestrain consolidation test and the hindered sedimentation test. The initial point pertaining to the latter test at a void ratio of 18 is not shown because of the negligible effective stresses during sedimentation. Figure $2 \mathrm{a}$, that depicts the test results on a semi-logarithmic scale, shows that the overall data best fits a bi-power law function. The lowest effective stress of about $0.1 \mathrm{kPa}$ was measured at $e=8.0$. This void ratio is called the maximum suspension void ratio $\left(e_{m}\right)$ that corresponds to the initial development of a distinct slurry microstructure (Azam et al., 2007). For the solid and liquid composition (given in Table 1), physicochemical interactions at phase boundaries resulted in a three-dimensional network that largely prevented the free fall of coarse particles and resisted self-weight settling at low effective stresses. According to Pane and Schiffman (1997), $e_{m}$ is a fundamental material property that is governed by solid-liquid interactions. When external loads were applied in the large-strain consolidation test, the figure indicates that physicochemical effects were overcome at an effective stress of $0.9 \mathrm{kPa}$.

The transition of the law was chosen from Figure $2 b$ where effective stress is plotted on an arithmetic scale. This plot shows that the effective stress starts to significantly increase around $e=6.5$. This void ratio is termed as the structural void ratio $\left(e_{s}\right)$ that refers to the development of a soil skeleton transferring effective stress through granular contact. Denoting compressibility parameters by $A_{1}, B_{1}, A_{2}$, and $B_{2}$, the constitutive relationships (best fits found to be bi-power law functions) for void ratio $(e)$ and effective stress $\left(\sigma^{\prime}, \mathrm{kPa}\right)$ were written as follows:

$e= \begin{cases}A_{1} \sigma^{\prime B_{1}} & \text { when } e \geq e_{s} \\ A_{2} \sigma^{\prime B_{2}} & \text { when } e<e_{s}\end{cases}$

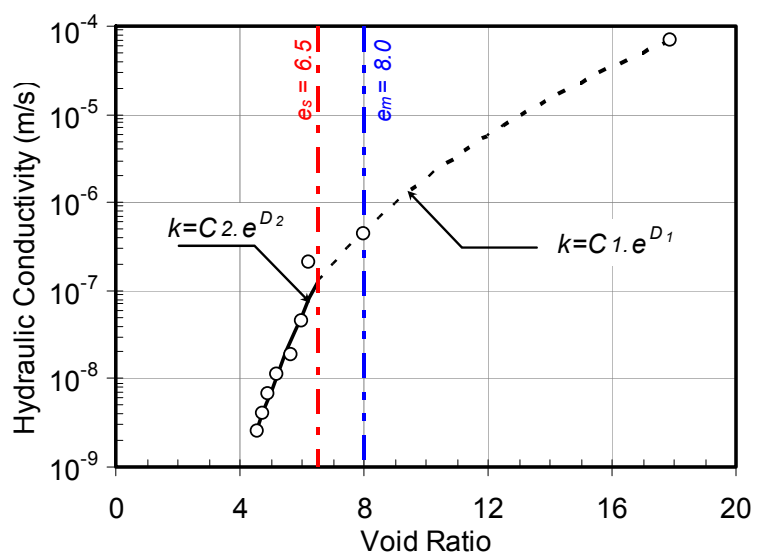

Figure 3. Tailings hydraulic conductivity.

Figure 3 gives the laboratory-determined hydraulic conductivity of the investigated tailings using the processed data from the large-strain consolidation test and the hindered sedimentation test. The initial point (at $e=18$ ) was determined from the sedimentation test using Equation (5). The hydraulic conductivity was found to vary by almost five orders of magnitude, that is, from $10^{-4} \mathrm{~m} / \mathrm{sec}$ (during hindered sedimentation) through about $10^{-9} \mathrm{~m} / \mathrm{sec}$ (during large-strain consolidation). These values are similar to published test data on other types of fine tailings (Qiu and Sego, 2001; Suthaker and Scott, 1996). As before, a bi-power law was found to best fit the hydraulic conductivity relationship. The abrupt change in hydraulic conductivity was observed to be at $e=e_{s}=6.5$ and represented 
the change in soil structure. Denoting the hydraulic conductivity parameters by $C_{1}, D_{1}, C_{2}$, and $D_{2}$, the constitutive relationships for hydraulic conductivity $(k, \mathrm{~m} / \mathrm{D})$ and void ratio $(e)$ were expressed as follows:

$$
k= \begin{cases}C_{1} e^{D_{1}} & \text { when } e \geq e_{s} \\ C_{2} e^{D_{2}} & \text { when } e<e_{s}\end{cases}
$$

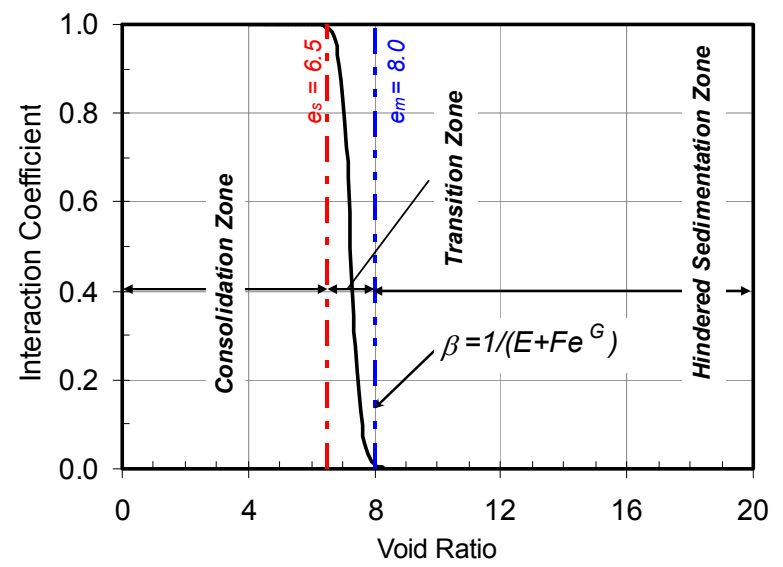

Figure 4. Variation of interaction coefficient with void ratio.

To perform the coupled sedimentation-consolidation analysis, the interaction coefficient, $\beta$, was varied from $e_{s}=6.5$ (onset of consolidation) to $e_{m}=8.0$ (completion of sedimentation). Using $E, F$, and $G$ as fitting parameters for the interaction coefficient, the following Weibull function was chosen for a smooth transformation between the two boundary void ratios:

$\beta=\frac{1}{\left(E+F e^{G}\right)}$

Figure 4 plots the variation of the interaction coefficient with void ratio. The coefficient divides the compressibility of the soil-water mixture into three zones: hindered settling $(\beta=$ $0.0)$; transition $(0.0 \leq \beta \leq 1.0)$; and consolidation $(\beta=1.0)$. Deformation in the transition zone is not governed by the principle of effective stress, that is, the slurry compresses to lower void ratios without excess pore pressure dissipation. According to Pane and Schiffman (1985), the solid-liquid mixture is neither a suspension nor a soil in this zone.

Table 2 gives the modeling parameters for both of the models. Jeeravipoolvarn (2005) conducted a sensitivity analysis of the modeling parameters for similar tailings. It was concluded that for short-term conditions such as in thickeners, the compressibility parameters $\left(A_{1}, B_{1}, A_{2}\right.$, and $\left.B_{2}\right)$ are essential to predict ultimate settlement but have little effect on the rate and amount of interface settlement estimates. Conversely, the hydraulic conductivity parameters $\left(C_{1}, D_{1}, C_{2}\right.$, and $\left.D_{2}\right)$ were found to govern both the rate and amount of settlement at a given time over short durations. Suthaker and Scott (1994) found similar results for oil sand tailings and concluded that hydraulic conductivity dominates the predicted settlement with time analysis whereas the void ratio-effective stress relationship is relatively insignificant in modeling the deposited tailings.

Table 2. Summary of Modeling Parameters

\begin{tabular}{lll}
\hline Parameter & $\begin{array}{l}\text { Nonlinear Finite } \\
\text { Strain Consolidation }\end{array}$ & $\begin{array}{l}\text { Coupled Sedimentation- } \\
\text { Consolidation }\end{array}$ \\
\hline$A_{1}$ & 6.17 & 6.17 \\
$B_{1}$ & -0.140 & -0.140 \\
$C_{1}$ & $9.00 \times 10^{-8}$ & $9.00 \times 10^{-8}$ \\
$D_{1}$ & 6.25 & 6.25 \\
$A_{2}$ & 6.30 & 6.30 \\
$B_{2}$ & $-8.50 \times 10^{-2}$ & $-8.50 \times 10^{-2}$ \\
$C_{2}$ & $1.99 \times 10^{-11}$ & $1.99 \times 10^{-11}$ \\
$D_{2}$ & 10.7 & 10.7 \\
$E$ & ---- & 1.0 \\
$F$ & ----- & $1.0 \times 10^{-40}$ \\
$G$ & ---- & 46.5 \\
\hline
\end{tabular}

A finite difference method with a backward time central space scheme was coded in Visual Basic to solve the governing equations: (1) for the nonlinear finite strain consolidation model and (3) for the coupled sedimentation-consolidation model. A total number of nodes, $n=100$ and an incremental time, $\Delta t=10^{-5} \mathrm{sec}$ were used in all of the simulations. This yielded a series of linear expressions, which were iteratively solved using the Gauss-Seidel method.

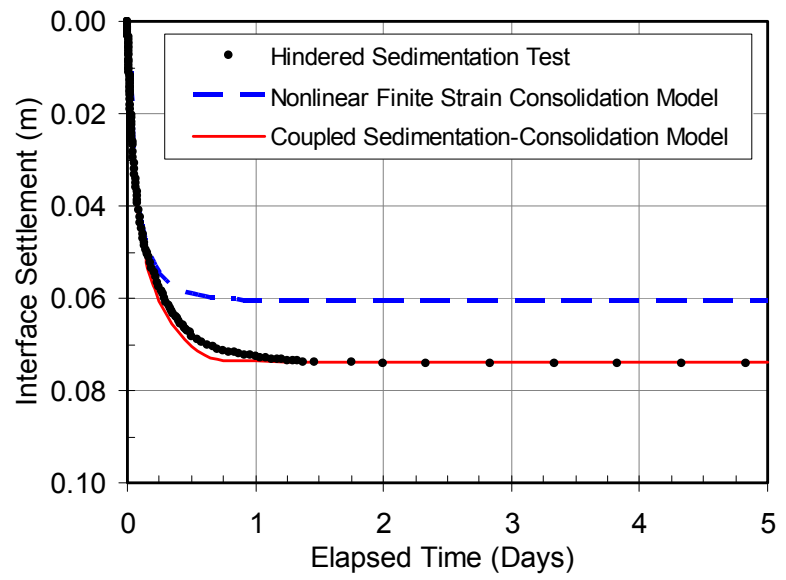

Figure 5. Comparison of interface settlement from numerical models and laboratory test.

\section{Model Validation}

To validate the models (that is, to determine the effectiveness of capture of the investigated settling behavior by the models), the interface settlement predictions from the two models were compared with the laboratory-measured hindered sedimentation test data. The governing equations were solved using initial and boundary conditions similar to the test condi- 
tions. The initial conditions were defined by a height of 133 $\mathrm{mm}$ and a void ratio of 18 . The initial void ratio was related to the constitutive relationships for compressibility (6) and hydraulic conductivity (7) as well as to the interaction coefficient (8). The boundary conditions included a drained state for the upper boundary and an undrained state for the lower and lateral boundaries.

Figure 5 compares the two models with the hindered sedimentation test results from the $133 \mathrm{~mm}$ standpipe. The nonlinear finite strain consolidation model was found to capture the initial interface settlement data from the standpipe test till about 0.1 days beyond which it under-predicted the same. Conversely, the coupled sedimentation-consolidation model matched the tailings-water interface more closely during compression and resulted in the same final settlement as the experimental data. These differences are attributed to the inherent assumptions in the constitutive relationships used to develop the two models. The former model followed the assigned power law compressibility functions whereas the interaction coefficient technique used in the latter model disregarded the initial compressibility above $e_{m}$. Therefore, the nonlinear finite strain consolidation model required less deformation to satisfy the self-weight effective stress compared to the coupled sedimentation-consolidation model. According to Azam et al. (2007), the influence of physicochemical interactions is overcome by the application of either external applied loads (such as longterm tailings consolidation in a pond) or internal surcharge loads (due to increasing solids content as at the base of a deeper containment).

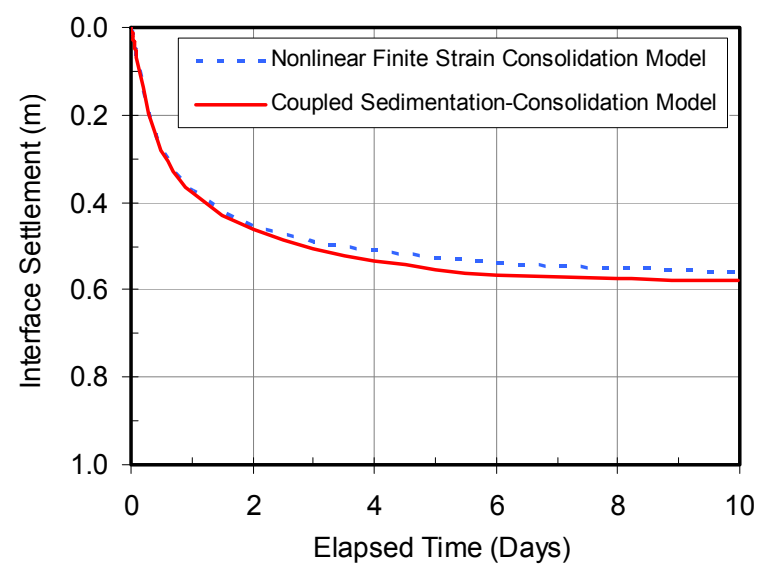

Figure 6. Predicted interface settlement for a $1.0 \mathrm{~m}$ deep thickener.

\section{Model Verification}

To verify the models (that is, to determine the effectiveness of capture of the conceptual settling process by the models), predictions for a hypothetical thickener from the two models were compared. A deposition height of $1.0 \mathrm{~m}$ and quiescent conditions were selected. All the other initial and boundary conditions were kept the same as before.
Figure 6 compares the two models for the $1.0 \mathrm{~m}$ deep thickener under quiescent conditions. Both models initially gave identical interface settlement predictions (up to about 1 day) beyond which a divergence was observed. However, the maximum difference in the interface settlement predictions of the two models was found to be only $3 \%$ of the initial slurry height in the containment. This small discrepancy was observed to be steadily decreasing over time. The uniqueness of the interface settlement predictions during hindered sedimentation (up to the end of 1 day) from both models verified that the physicochemical interactions govern the thickening process. Furthermore, both of the models can provide reasonably accurate estimates of tailings dewatering during consolidation as indicated by the close match of their predictions (day 6 through day 10). This is because the governing equations for both models are identical for consolidation when the interaction coefficient is equal to 1 .
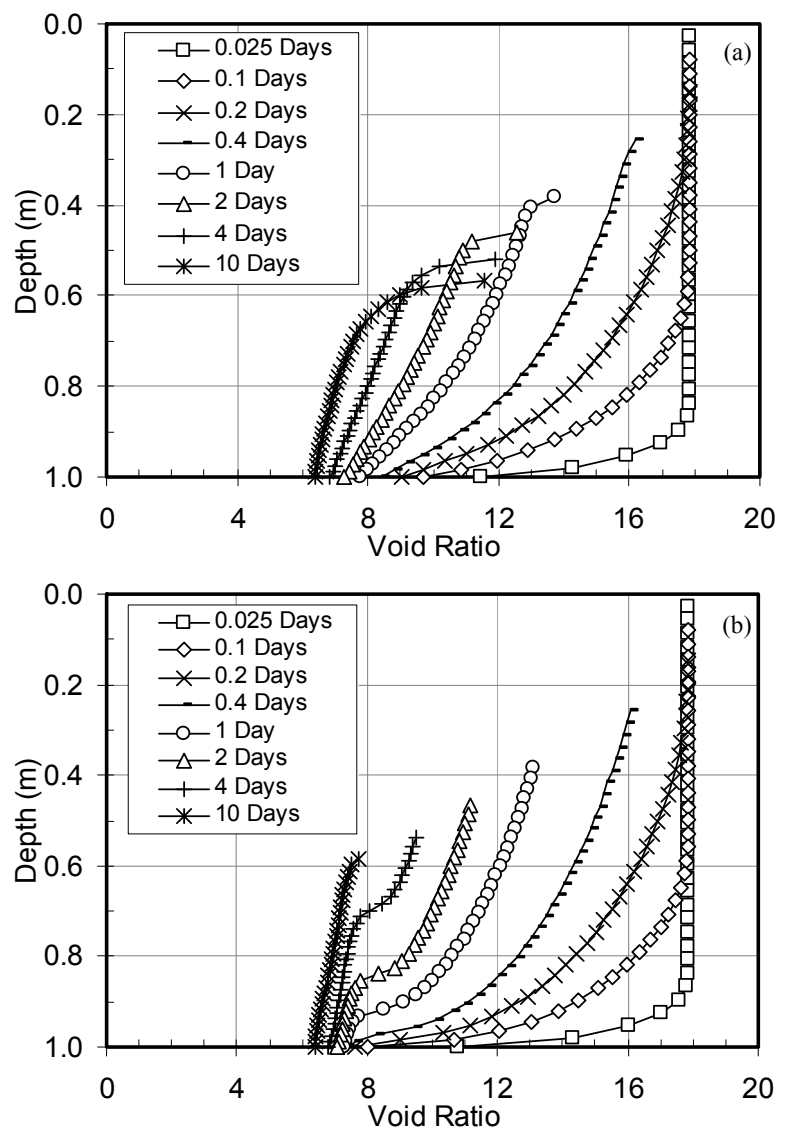

Figure 7. Predicted void ratio profile for a $1.0 \mathrm{~m}$ deep thickener: (a) nonlinear finite strain consolidation model and (b) coupled sedimentation-consolidation model.

Figure 7 gives the predicted void ratio profiles for a 1.0 $m$ deep thickener at various elapsed times during compression. The two models provided similar predictions for up to 0.2 days when sedimentation dominated the thickening process. At ti- 


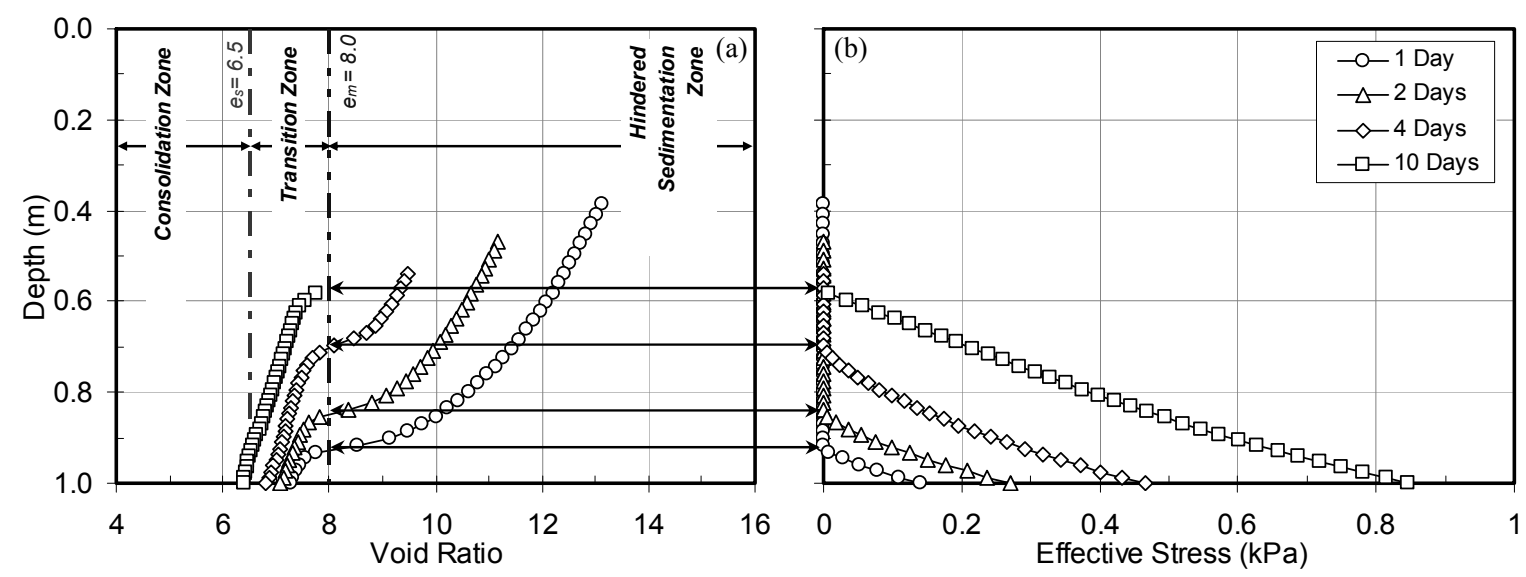

Figure 8. Predicted thickening profiles using the coupled sedimentation-consolidation model: (a) void ratio and (b) effective stress.

mes greater than 0.2 days, the first model depicted a steady decrease in void ratio with depth whereas the latter model gave a distinct transitioning layer indicated by the concave upward deflection in the profiles. This layer gradually accumulated towards the top of the deposit at the expense of a diminishing slurry zone undergoing hindered sedimentation. This comparison indicates that the coupled sedimentation-consolidation model provides additional information about the transition of a dilute slurry to a soil transmitting effective stresses through granular contacts.

Figure 8 plots the predicted profiles for elapsed times of $1,2,4$, and 10 days using the coupled sedimentation-consolidation model. Using $e_{s}=6.5$ and $e_{m}=8.0$, the void ratio profile (Figure $8 \mathrm{a}$ ) distinguishes between a consolidation zone, a transition zone and a hindered sedimentation zone. Under hindered sedimentation conditions, the effective stress is essentially zero (as indicated by the effective stress profile shown in Figure 8b) and the solid particles travel en-masse downward to the bottom of the $1.0 \mathrm{~m}$ deep thickener. As the particles rearrange to a denser state at $e_{m}$, their proximity may allow partial stress transfer at granular contacts. However, physicochemical interactions at phase boundaries are dominant at this stage and result in measurable effective stresses (small deviations from the ordinate in Figure $8 \mathrm{~b}$ ). As the self-weight stresses of the mixture further compresses the settled particles to a lower void ratio $\left(e_{s}\right)$, the soil skeleton is fully developed and the slurry becomes a soil transmitting effective stresses at granular contacts in the consolidation zone.

Figure 9 shows a comparison of the two models using the 10 day void ratio profiles. As expected, both of the models provided identical values during consolidation, that is, for $e_{s} \leq$ 6.5 because the Terzaghi's principle of effective stress can be fully applied in both models. The profiles were found to diverge at higher void ratios such that at any given depth the void ratio predicted by the nonlinear finite strain consolidation model was always higher than that estimated by the coupled sedimentation-consolidation model. This is attributed to the fact that in the latter model, the effective stress is essentially quite small at void ratios above 6.5 in comparison to the former model, and thus, the solid particles have to be compressed to a lower and more stable void ratio.

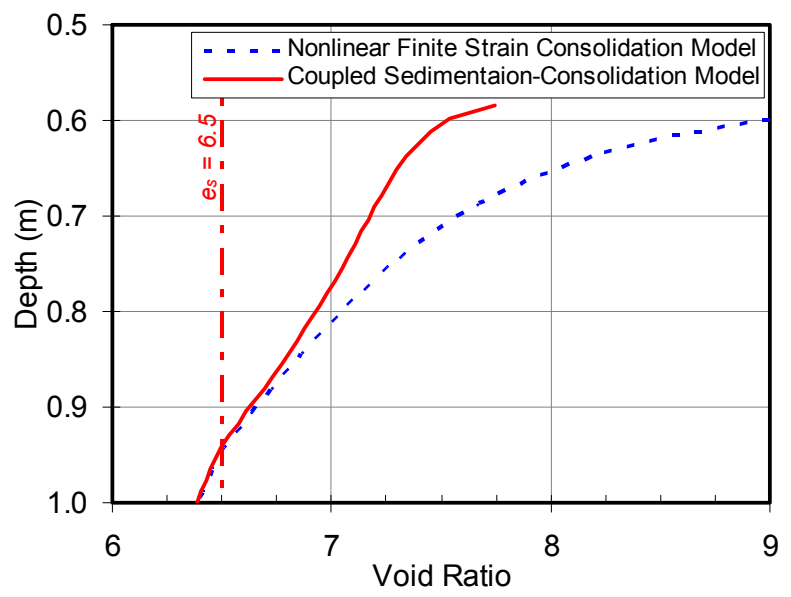

Figure 9. Model comparison using 10 day void ratio profiles.

\section{Discussion}

The models presented herein provided similar predictions during consolidation but differing predictions during sedimentation. This is because the coupled sedimentation-consolidation model captured the physicochemical interactions (derived from solid and liquid compositions) that govern the settling behavior of dilute slurries such as those in gravity thickeners. Whereas similar results are expected for other slurries, the models must be calibrated to incorporate the effect of solid and liquid compositions when applied to various types of tailings. Furthermore, the composition of additives (such as natural coagulants and/or polymeric flocculants) has to be included in the models if such materials are used for improving the thickening process.

The initial conditions play a significant role in determining the rate and amount of slurry settling. Variations in the initial solids content (affecting the development of an initial slurry microstructure) result in variations in slurry behavior during sedimentation. Particle segregation at low solids con- 
tents and fabric denseness at increasing solids content can cause inconsistency in model predictions. Azam et al. (2007) showed that there is no unique effective stress-void ratio relationship at low effective stresses. Based on measured laboratory data $\left(e=2.7\right.$ through 1.5 and $\sigma^{\prime}=0.1 \mathrm{kPa}$ through $2.0 \mathrm{kPa})$, it was found that the higher the initial solids content (lower void ratio and a dense microstructure), the higher the solids content throughout the test. Although the initial deposition height has no effect on the initial hydraulic conductivity determined during hindered sedimentation, this parameter has been shown to affect the ultimate interface settlement of slurries (Pane and Schiffman, 1997). These authors concluded that a higher initial deposition height is associated with a higher final sediment height (that is, a loose sediment) and vice versa. Such measured data should be used for further model validation, especially for the coupled sedimentation-consolidation model.

The models were verified for a $1.0 \mathrm{~m}$ hypothetical thickener under quiescent conditions. With appropriate changes in computer programming, both of the models can be adopted to predict the slurry thickening behavior in larger and continuously filled thickeners with underflow withdrawn at regular intervals. Further, the models can be applied to thickened tailings streams (thickener underflow at higher solids content) developed for surface deposition, mine backfilling, or sub-aqueous discharge. The boundary conditions have to be modified to depict field situations such as lateral drainage and surface desiccation in thickened tailings deposits. In such applications, the two models may yield identical results if the consolidation stage is predominant.

\section{Conclusions}

Geotechnical engineers have traditionally used some form of the nonlinear finite strain consolidation model to develop management strategies for tailings containment facilities. Such models can be modified to capture the influence of physicochemical interactions during thickening of mine waste tailings. This study included the hindered sedimentation regime in the finite strain consolidation theory to develop a coupled sedimentation-consolidation model. The transition zone was numerically modeled between a maximum suspension void ratio corresponding to the initial development of a distinct slurry microstructure and a structural void ratio referring to the development of a soil skeleton transferring effective stresses. For the investigated tailings material, sedimentation was found to be complete at $e_{m}=8.0$ and consolidation was observed to start at $e_{s}=6.5$. Both of the models closely matched at $e \leq 6.5$ thereby confirming the validity of the coupled sedimentationconsolidation model.

Acknowledgments. The authors acknowledge the financial support of Dynatec Corporation, Canada. Thanks to the University of Regina and the University of Alberta for providing computing facilities.

\section{References}

Azam, S., Scott, J.D., and Jeeravipoolvarn, S. (2007). When does a slurry become a soil? Geotechnical News. BiTech, BC, 25(3), 44-46.

Azam, S., Chalaturnyk, R., and Scott, J.D. (2005). Geotechnical characterization and sedimentation behavior of laterite slurries, Geotech. Test. J., 28(6), 523-533, doi:10.1520/GTJ12511.

Been, K., and Sills, G.C. (1981). Self-weight consolidation of soft soils - an experimental and theoretical study, Géotechnique, 31(4), 519-535.

Concha, F., Burger, R. (2003). Thickening in the 20th Century: a historical perspective, Mineral \& Metallurgical Processing, 20, 5767.

Eckert, W.F., Masliyah, J.H., Gray, M.R., and Fedorak, P.M. (1996). Prediction of sedimentation and consolidation of fine tails, American Institute of Chemical Engineers Journal, 42, 960-972.

Edil, T.B., and Fox, P.J. (2000). Geotechnics of High Water Content Materials, ASTM, PA.

Gibson, R.E., England, G.L., and Hussey, M.J.L. (1967). The theory of one dimensional consolidation of saturated clays: Finite strain consolidation of thick homogeneous layers, Géotechnique, 17, 261-273.

Imai, G. (1981). Experimental studies on sedimentation mechanism and sediment formation of clay materials, Soils and Foundations, 21, 7-20.

Jeeravipoolvarn, S. (2005). Compression Behaviour of Thixotropic Oil Sands Tailings, M.Sc. Thesis, University of Alberta.

Jeeravipoolvarn, S., Chalaturnyk, R.J., and Scott, J.D. (2009). Sedimentation-consolidation modeling with an interaction coefficient, Comput. Geotech., In Press.

Jewell, R.J., and Fourie, A.B. (2006). Paste and Thickened Tailings- $A$ Guide, 2nd ed., Australian Centre for Geomechanics, Nedlands.

Kynch G.J. (1952). A theory of sedimentation, Transactions of Faraday Society, 48, 166-176.

McRoberts E.C., and Nixon J.F. (1976). A theory of soil sedimentation, Can. Geotech. J., 13, 294-310.

Morgenstern, N.R., and Scott, J.D. (1995). Geotechnics of fine tailings management, Proceedings, Specialty Conference on Geotechnical Practice in Waste Disposal, LA. 2, 1663-1683.

Pane, V., and Schiffman, R.L. (1997). The permeability of clay suspensions, Géotechnique, 47, 273-288.

Pane, V., and Schiffman, R.L. (1985). A note on sedimentation and consolidation, Géotechnique, 35, 69-72.

Qiu, Y., and Sego, D.C. (2001). Laboratory properties of mine tailings, Can. Geotech. J., 38(1), 183-190.

Robinsky, E.I. (1999). Thickened Tailings Disposal in the Mining Industry, Quebecor Printpak.

Suthaker, N.N., and Scott, J.D. (1996). Measurement of hydraulic conductivity in oil sand tailings slurries, Can. Geotech. J., 33(4), 642-653, doi:10.1139/cgj-34-4-637.

Suthaker, N.N., and Scott, J.D. (1994). Large strain consolidation testing of oil sand fine tails in a wet landscape, Proceedings, 47th Canadian Geotechnical Conference, Hailfax. 1, 514-523.

Terzaghi, K, Peck, R.B., and Mesri, G. (1996). Soil Mechanics in Engineering Practice, 3rd ed.,Wiley.

Toorman, E.A. (1999). Sedimentation and self-weight consolidation: constitutive equations and numerical modeling, Géotechnique, 49, 709-726. 